\title{
ANOREXIA: UMA PSEUDO-SEPARAÇÃO FRENTE A IMPASSES NA ALIENAÇÃO E NA SEPARAÇÃO
}

Alinne Nogueira Silva*

Angélica Bastos**

\section{Resumo}

O presente trabalho versa sobre a anorexia nos quadros de neurose e tem por objetivo detectar as dificuldades com que se defronta a psicanálise nos casos de sujeitos que recusam a alimentação. Segundo uma abordagem teórico-clínica, o artigo parte do sintoma anoréxico, tal como ele se apresenta no plano dos fenômenos, e investiga sua articulação com o plano estrutural na fantasia neurótica. Admite-se a premissa de que a anorexia, mais que uma recusa de comer, afirma-se como um "comer nada". Assim, procede-se a uma investigação sobre o "nada", aqui entendido como um objeto. A fim de conceituar essa modalidade de objeto, recorre-se à teoria lacaniana da constituição do sujeito segundo as operações de alienação e separação. Examina-se a fantasia de desaparecimento e discutem-se o êxito e o impasse da separação, quando esta se estabelece às custas de uma estratégia anoréxica.

Palavras-chave: psicanálise, anorexia, nada, separação, sujeito, desejo

\section{AbSTRACT}

ANOREXIA: A PSEUDO-SEPARATION IN THE LIGHT OF THE IMPASSES ON ALIENATION AND SEPARATION

This paper discusses the anorexia present in the cases of neurosis and is aimed at detecting the difficulties that psychoanalysis faces when the subjects refuse to be fed. According to a theoretical-clinical approach, the article starts from the anorexic symptom as it is presented in the phenomena level and investigates its articulation with the structural level of neurotic fantasy. It is assumed that anorexia, more than a refusal of eating, is reassured as "eating nothing". So,

* Universidade Federal de Juiz de Fora, Professora da pós-graduação em psicanálise e cultura.

** Professora Adjunta do Programa de Pós-Graduação em Psicologia - UFRJ, Psicanalista. 
an investigation is taken about this "nothing" as it is here understood as an object. In order to classify this kind of object, we have turned to the Lacanian theory of subject constitution according to the operations of alienation and separation. In this situation, the fantasy of disappearance is examined, success and the impasse of separation are discussed when it is established at the cost of an anorexic strategy.

Keywords: psychoanalysis, anorexia, "nothing", separation, subject, desire

Este artigo interroga o sintoma da anorexia nos quadros de neurose, com o objetivo de apontar os impasses subjetivos a que corresponde. Muito presentes na clínica psicanalítica contemporânea, os casos que se destacam pelo sintoma anoréxico constituem um desafio para o analista.

Sabe-se que a anorexia surge nas mais variadas modalidades clínicas, como a melancolia, o autismo, os estados que antecedem o surto na psicose ou nas psicoses declaradas. Quando menciona a anorexia, Freud a toma numa dimensão sintomática, ou seja, refere-se ao sintoma anoréxico e não a anoréxicas em particular, nem a uma categoria clínica isolada. Desde suas correspondências com Fliess, afirma que "a neurose nutricional paralela à melancolia é a anorexia. A famosa anorexia nervosa [...] é uma melancolia em que a sexualidade não se desenvolveu. [...] Perda do apetite - em termos sexuais, perda de libido" (Freud, 1892-1899/ 1950: 247).

Relacionando a perda de apetite e a perda de libido com uma perda objetal, encontramos o caminho pelo qual Freud articulou a anorexia com a melancolia. Ambas resultam de uma dificuldade do sujeito em lidar com a perda do objeto. $\mathrm{O}$ processo anoréxico revela uma dificuldade em relação à perda, à realização de um luto. Nesse momento de sua obra, essa perda de libido pode ser entendida como uma deserotização da atividade oral, já que, aqui, a anorexia é articulada com a melancolia. Em nenhum outro momento, porém, Freud fará esse paralelo, passando a relacionar a anorexia com a histeria e, conseqüentemente, com um aumento da erotização na zona oral que perturba as atividades aí situadas.

Ao limitarmos nossa investigação à estrutura neurótica, não pretendemos interpretar esse sintoma ou conferir-lhe um sentido unívoco, nem torná-lo genérico ou homogêneo no conjunto de casos de neurose, mas sim alçá-lo ao plano da fantasia para abordá-lo em sua relação com o desejo. Assim, pretende-se passar do plano dos fenômenos ao da estrutura neurótica. Para isso, colocamos a problemática em termos da constituição subjetiva na neurose, vale dizer, nos termos dos processos de alienação e separação, que envolvem o sujeito e o Outro. 
Por sua forma radical de apresentação, por seu "não" constante diante do alimento que lhe é ofertado e, sobretudo, pela recusa renitente diante da demanda do Outro, muitas vezes a anorexia é vista como separação. Podemos realmente falar de uma separação? Visto ser a anorexia um sintoma que definha o corpo, podendo levar à morte, não seria ela uma separação mal sucedida ou em impasse? Com o intuito de abordarmos a articulação da anorexia com a alteridade e com o desejo, pautaremos nossa discussão em alguns comentários de Jacques Lacan sobre a anorexia, o nada e a fantasia de desaparecimento.

Entendemos a anorexia como "um comer nada" (Lacan, 1956-57/1995: 188) e não como um "não comer". Ela se apresenta como um sintoma que coloca em ato a falta através desse nada. Comer nada é uma maneira encontrada pelo sujeito para introduzir uma falta no Outro, para interpor um "não" à "papinha sufocante" (Lacan, 1958/1998: 634) que o Outro oferece incessantemente.

Essa forma de o sujeito colocar-se diante do Outro, vale dizer, o estabelecimento de uma defasagem entre o que se obtém e o que se deseja possui algo de estrutural, sendo constitutivo do sujeito. As crianças, num momento precoce, passam a recusar, senão toda alimentação - esse seria o caso extremo da anorexia -, algum tipo de alimento, traduzindo com suas predileções e aversões, com o gostar de uma coisa ao invés de outra, um movimento de subjetivação. Isso se aplica às anorexias leves e passageiras nos primeiros anos da infância, quando a criança se mostra inapetente. O que há de peculiar no processo de constituição do sujeito, quando ele vem a produzir esse sintoma, quando o cristaliza, fazendo da anorexia sua resposta?

A partir do ensino lacaniano, pode-se afirmar que na anorexia o Outro primordial, ao ser convocado no lugar daquele que não tem, daquele marcado pela falta, responde com o alimento, ou seja, "confunde seus cuidados com o dom de seu amor” (Lacan, 1958/1998: 634). Diante da angústia por não saber o que o sujeito lhe está demandando, por não entender o que o choro do bebê significa, o Outro responde com o alimento, ou seja, reduz a falta à falta de alimento. O sujeito, massacrado pelos cuidados do Outro, encontra como solução, como via de sustentação do desejo, a recusa do objeto oral. O sujeito propõe que o Outro busque um objeto de desejo além dele, fora dele, porque assim ele próprio encontrará o rumo do desejo. Recusar o alimento é, portanto, uma forma de assegurar que algo falta ao Outro, que a falta não pode ser reduzida à falta de alimento, e mais, que a falta é estrutural, não podendo ser suprimida por nenhum objeto.

O desejo é indestrutível e nenhuma satisfação obtida através de um objeto da realidade pode preencher a falta do sujeito. É assim que Lacan afirma que "mesmo o desejo da criança nunca está ligado à pura e simples satisfação natural" (Lacan, 1956-57/1995: 186) ou corporal. 
Sublinhemos que a recusa aparece associada a um nada, ou melhor, através da recusa o sujeito coloca em ato a presença do nada. É importante ressaltar que a recusa na anorexia não se confunde com a da castração; pelo contrário, recusa-se que um objeto possa saturar o que é da ordem do desejo, ou seja, trata-se da recusa de um objeto. Vista por esse prisma, a anorexia seria, então, uma manobra de separação do sujeito em relação ao Outro. Aí onde o Outro parece sufocar toda falta, a recusa surge como desejo, ou seja, é nos meandros da relação entre o sujeito e o Outro que se encontra o sintoma da anorexia.

Como se constitui o sujeito? Se ele não pode ser definido como consciência de si, como aquele que coordena o sentido, como concebê-lo? Não se nasce sujeito do desejo. O sujeito surge a partir do movimento de alienação e separação da cadeia de significantes. "O registro do significante institui-se pelo fato de um significante representar um sujeito para outro significante. Essa é a estrutura, sonho, lapso e chiste, de todas as formações do inconsciente. E é também o que explica a divisão originária do sujeito" (Lacan, 1960/1998: 849).

O sujeito advém a partir de uma estrutura que se coloca desde antes de seu nascimento, a estrutura da linguagem. É na dinâmica da linguagem, na relação entre significantes, que Lacan localiza a causa do sujeito. Em suas palavras, "o efeito de linguagem é a causa introduzida no sujeito. Por esse efeito, ele não é causa dele mesmo, mas traz em si o germe da sua causa que o cinde" (Lacan, 1960/1998: 849).

O sujeito surge cindido, cortado em sua estrutura. Lacan (1964/1986) formula a constituição do sujeito, utilizando, para isso, duas operações que funcionam de modo conjugado: a alienação e a separação. Trabalhemos com a hipótese segundo a qual o sintoma da anorexia, como resposta do sujeito, traduz sua posição nos movimentos de alienação e separação.

Sustentando a constituição da psicanálise como campo do inconsciente - o que já se encontrava definido no axioma segundo o qual o inconsciente é estruturado como uma linguagem (Lacan, 1955-56/1988) -, Lacan (1960/1998) acrescenta uma nova articulação: à alienação do sujeito nos significantes do Outro, no campo da linguagem, associa a separação, mostrando assim que o campo do Outro não é todo significante; que há um núcleo não significantizável, o objeto $a$, objeto peculiar, posto que traduz a falta que afeta tanto o sujeito quanto o Outro. Essa falta é o pivô da separação: para que o sujeito se separe da cadeia significante, para que não fique inteiramente preso aos significantes do Outro, é preciso que a falta opere.

As duas operações que definem o sujeito, a alienação e a separação, são compreendidas a partir da relação entre o que Lacan chamou de campo do vivo (ainda 
não há sujeito) e o campo do Outro, aqui definido como lugar da linguagem, do sentido, onde irá aparecer o sujeito.

No que concerne à alienação, vemos que o sujeito só pode ser conhecido no lugar do Outro. Isso porque o Outro precede o sujeito; fala-se dele antes mesmo de seu nascimento e a fala depende desse campo. Há uma diferença entre o campo do ser vivo e o do sujeito. O sujeito surge ao preço de uma perda de parte desse vivo, devido à própria estrutura da linguagem. Sendo assim, na alienação do sujeito ao campo do Outro, uma perda está necessariamente envolvida como contrapartida do acesso ao sentido.

O sujeito se faz representar por um significante, o qual terá que representálo para um outro significante, uma vez que um significante sozinho não representa nada. A representação está, pois, articulada à idéia de cadeia. Nesse sentido, o sujeito se presentifica no campo do Outro, já que se constitui através do significante que aí se encontra.

É importante destacar que a alienação não é entendida como dependência em relação ao Outro e nem está relacionada com o fato de essa operação se iniciar no campo do Outro. Nas palavras de Lacan: "portanto, não é o fato de essa operação se iniciar no Outro que a faz qualificar de alienação. Que o Outro seja para o sujeito o lugar de sua causa significante só faz explicar aqui a razão por que nenhum sujeito pode ser causa de si mesmo" (Lacan, 1960/1998: 855).

Significante e sentido situam-se do lado do Outro, já que não cabe ao sujeito determinar um sentido ao significante. $\mathrm{O}$ sentido vem sempre como retorno da interpretação dada pelo Outro. Esse postulado já se encontra presente na obra de Freud (1895/1950) com a experiência de satisfação. Ali é o Outro que significa o choro do bebê, e é esse sentido que irá guiá-lo para uma ação específica em relação ao desamparo do bebê.

Lacan explicita essa relação entre o sujeito e o Outro com a utilização do termo vel, originário do latim, que possui o sentido de "ou". Mas o "ou" em jogo na alienação não possui um sentido excludente, como o apresentado na alternativa "como isso ou como aquilo", assim como também não tem uma aplicação de "tanto faz isso quanto aquilo". O vel implicado na operação de alienação envolve uma perda nos dois campos. O exemplo com que Lacan demonstra a função desse "ou" na alienação é a escolha que o sujeito tem que fazer entre a bolsa ou a vida. Nessa situação, se o sujeito escolhe a bolsa, fica sem a vida e sem a bolsa, e, se ele opta pela vida, tem que ceder a bolsa. Há, portanto, uma perda em qualquer escolha que se faça.

Esse processo se impõe a todo falante, mas não se pode dizer que ocorra sempre da mesma maneira para todos que são afetados pela linguagem. Por um 
lado, "A alienação é o destino" (Soller, 1997: 62), o caminho pelo qual o falante tem que passar, visto que é impossível estar fora da linguagem. Sendo assim, "o ser está fadado à perda, pois linguagem implica perda de ser. $\mathrm{O}$ vel da alienação mostra que, onde há linguagem, mesmo aquele que se recusa à fala não preserva seu ser" (Bastos, 2003: 145). Trata-se, portanto de uma escolha de muita pouca escolha, ou seja, uma escolha forçada, visto que optar pelo ser, ou, no exemplo lacaniano, pela bolsa, é recusar os significantes, o sentido do Outro, posição que levaria, em última instância, à morte, ou à impossibilidade de vida simbólica. Por outro lado, para não ficar retido nas malhas significantes, o sujeito que consentiu na alienação aciona estratégias de separação de acordo com o que pode localizar no Outro como falta. A anorexia ilustra bem que há diferentes saídas para a separação, saídas que não são independentes do modo com que se efetua a alienação.

A falta está relacionada com a sexualidade, com o caráter parcial da pulsão, em última instância, com a impossibilidade de representar a totalidade da tendência sexual. Daí resulta a ausência de uma definição ou inscrição sobre o sexo, sobre ser homem e ser mulher do ponto de vista do inconsciente. $\mathrm{O}$ que produz essa falta no campo do sujeito é o fato de ele estar determinado pela linguagem, sem a possibilidade de satisfação plena, faltando sempre algo em seus encontros com o Outro. Nas suas relações com o Outro, um vazio se faz presente, vazio responsável por uma busca constante à medida que se torna causa do desejo.

O ponto fundamental que destacamos no processo de alienação é o fato de que, ao ser dado um sentido para o sujeito, com os significantes que o Outro profere, há a possibilidade de surgir, para o primeiro, uma questão: que sentido é esse que eu recebo? O que o Outro quer dizer com isso que ele diz de mim? Por esse sentido ser formulado por significantes, uma falta pode aparecer, visto que ela está contida na própria cadeia de significantes. A equivocação se faz possível entre o que o Outro diz e o que está por trás disso. Esse movimento, por parte do sujeito, de querer saber o que é, para além do que o Outro diz sobre ele, indica um movimento de separação. A mãe encarna o primeiro Outro e dá um sentido ao sujeito, cabendo a ele se interrogar sobre o que ela diz. Esse questionamento da fala do Outro só pode ser realizado quando o sujeito se depara com uma falta no Outro, surgindo a possibilidade de separação. O desejo do Outro é a presença de alguma coisa que falta na fala.

Como vemos, então, enquanto na alienação trata-se de reunir o sujeito ao campo do Outro, no processo de separação ressalta-se a interseção entre esses dois campos. A interseção entre dois conjuntos é a operação que destaca o que pertence a ambos. Mas o que Lacan indica como sendo esse elemento comum - presente tanto no campo do sujeito como no campo do Outro - é a falta, digamos mate- 
maticamente, o conjunto vazio $[\varnothing]$ contido em todo conjunto. Vemos aqui uma aproximação entre falta e vazio no processo de alienação e separação, apontando para uma perda tanto no campo do ser quanto no campo do Outro.

As duas faltas que se recobrem na separação são: do lado do sujeito, o fato de ele não poder ser inteiramente representado no Outro. $\mathrm{O}$ significante induz uma perda de ser, deixando um resto, resíduo que definirá o seu ser sexual. Do lado do Outro, a falta que vigora na separação é aquela que o torna desejante. Esta falta se encena com a perda do sujeito, vale dizer, com seu desaparecimento enquanto objeto que causa o desejo do Outro.

Lacan assinala que é no processo de separação que se fecha a causação do sujeito, onde se reconhece a sua fenda. Ele nos diz "separare, separar, conclui-se aqui em selparere, gerar a si mesmo" (Lacan, 1960/1998: 857). A separação é trabalhada a partir de sua estreita relação com a causa do desejo, com o que resta dessa operação e não diz respeito ao significante. Trata-se do objeto $a$, que não é o objeto do desejo e sim aquele que move o desejo, sua causa.

É um desejo, uma falta que se apresenta através da articulação da cadeia significante, que faz com que o sujeito questione o lugar que ele ocupa frente ao Outro. Lacan (1964/1986) chega a afirmar que "a função do desejo é resíduo último do efeito do significante no sujeito” (Lacan, 1964/1986: 147). Há sempre um resto irrepresentável que cai da cadeia de significante, mostrando que aí se produz uma falta, o objeto $a$.

O ponto que Lacan destaca a partir desse movimento de separação, e que se faz central para a abordagem da anorexia, é o oferecimento do sujeito, mais especificamente de seu desaparecimento, diante do enigma do desejo do Outro: "o primeiro objeto que ele propõe a esse desejo parental cujo objeto é desconhecido é sua própria perda. Pode ele me perder?” (Lacan, 1964/1986: 203). Diante desse não saber sobre o desejo do Outro, o sujeito se coloca, se faz representar, através de seu desaparecimento. Nesse momento, Lacan afirma que "a fantasia de sua própria morte, de seu desaparecimento, é o primeiro objeto que o sujeito tem a pôr em jogo nessa dialética, e ele o põe, com efeito - sabemos disso por mil fatos, ainda que fosse pela anorexia mental" (Lacan, 1964/1986: 203).

A anorexia presentifica esse momento em que o sujeito convoca o desejo do Outro. Além disso, ela retrata a posição daquele que quer saber até que ponto o Outro o quer, qual o limite desse querer. Esta posição é uma tentativa de tatear o desejo do Outro.

Podemos afirmar que a anorexia aparece como uma resposta do sujeito à opacidade do desejo parental sob a forma de uma fantasia de desaparecimento. Esta é, então, uma das fantasias passíveis de serem formuladas a partir do enigma 
do desejo do Outro - o oferecimento ao Outro, por parte do sujeito, de seu desaparecimento. Assim, o sujeito se refugia na fantasia de sua própria morte face à dificuldade, ou à impossibilidade, de saber sobre o Outro.

É justamente quando o sujeito se depara com o desejo do Outro em sua vida, seja nas transformaçôes que o corpo sofre na adolescência, seja em seu encontro com o sexo, que a anorexia aparece. Ressaltamos a semelhança entre o questionamento diante do qual o sujeito oferece seu desaparecimento ao Outro "o que o Outro quer de mim?" - e a pergunta que surge sobretudo com a chegada da adolescência e com o encontro do sujeito com o sexo - "o que é ser mulher?" ou "como ser uma mulher frente ao Outro?". O fantasma de seu desaparecimento seria uma forçagem radical do desejo no Outro. Nesse sentido, o "sujeito se propõe como o objeto que poderia faltar ao desejo parental" (Wachsberger, 1998: 13). Assim, a anoréxica se identifica, encarna em sua fantasia o objeto perdido pelo Outro. Comendo o nada, ela tem a intenção de cavar uma falta no Outro com seu desaparecimento. Como nos diz Lacan (1964/1986), "é no que seu desejo está para além ou para aquém no que ela (mãe) diz, do que ela intima, do que ela faz sentir como sentido, é no que seu desejo é desconhecido, é nesse ponto de falta que se constitui o desejo do sujeito" (Lacan, 1964/1986: 207).

Quando se diz que é necessário um querer, um desejo do sujeito para que se estabeleça esse movimento de separação, recordemos que a criança, ao contrário do que se pensa, não é desmamada; ela se desmama, ela se separa do seio. Assim,

Se já não houvesse nisso algo tão ativo que podemos enunciá-lo no sentido de um desejo de desmame, como poderíamos sequer conceber os fatos sumamente primitivos, sumamente primordiais em seu aparecimento, da recusa do seio, as formas primárias da anorexia, cujas correlações no nível do grande Outro nossa experiência nos ensina imediatamente a procurar (Lacan, 1962-63/2005: 356)?

A separação está ligada à admissão de que o Outro também está submetido à lei significante e, mais ainda, a uma lei que o coloca como faltoso, como desejante. O processo de separação está, assim, relacionado à castração do Outro. Ele envolve um desejo do sujeito, e a citação acima só confirma a presença desse movimento no sintoma da anorexia.

Seguindo nesse caminho que apresenta a anorexia como uma tentativa de separação, recorremos a J. A. Miller (2000), que utiliza os movimentos de alienação e separação ordenando a anorexia "do lado do sujeito barrado, do lado da separação. É a estrutura de qualquer desejo; a rejeição da mãe nutridora e, mais amplamente, a rejeição do Outro é o que nela está em primeiro plano" (Miller, 
2000: 177). Uma das maneiras de observarmos esse afastamento do Outro é a evitação, o isolamento que a anoréxica demonstra em relação ao contato social.

Tal relação entre a anorexia e a separação também se faz presente em Rabinovich (1993), que relaciona a anorexia com essa posição de vampiro que o Outro pode ocupar na fantasia do sujeito.

O corte, a separação do desmame, se produz entre o seio e a mãe; para a criança, o seio materno é o desejo do Outro em ato, sob a forma do vampiro, por exemplo. Às vezes, tomemos como exemplo certas anorexias prematuras, há tal pregnância da posição de vampiro no desejo do Outro que a criança só pode se safar do desejo de alimentar, ou, se preferirem, do desejo de dar, e da posição de objeto do dito desejo via anorexia (Rabinovich, 1993: 104).

$\mathrm{Na}$ anorexia, onde o nada aparece como uma tentativa de separação do Outro, o corpo se consome para abrir uma falta no Outro. Apesar de, aparentemente, situar-se no horizonte do descarnado, esse corpo esquelético, cada vez mais magro e fraco, traz consigo uma marca fálica, um valor de troca nas relaçôes com o Outro.

Foi com os estudos de Massimo Recalcati (2001), juntamente com os citados aqui, que conseguimos avançar em nossas pesquisas sobre a anorexia. Segundo o autor, o movimento presente no sintoma da anorexia pode ser considerado uma pseudo-separação, e não uma separação do Outro. Isso é afirmado a partir da clínica, quando se verifica que a anoréxica recusa a demanda do Outro, põe à prova o desejo do Outro para sustentar sua onipotência, ou seja, ela busca essa separação pelo caminho da negação do Outro. Recalcati chega a classificar essa pseudo-separação como um movimento de "separação contra alienação" (Recalcati, 2001: 29), visto que ela tenta negar sua determinação pelo Outro na alienação originária. É o que demonstra sua recusa radical a qualquer objeto que a satisfaça, atitude que a coloca em um lugar (ilusório) de onipotência frente a todos: família, médico, psicólogo, em suma, frente ao Outro. "Na anorexia, de fato, a separação do Outro se configura como um modo para negar a dependência estrutural (simbólica) do sujeito ao Outro. É uma separação que aponta o desvincular-se da alienação" (Recalcati, 2001: 29). Posto que alienação e separação são processos conjugados, os percalços nesta última indicam o quanto o sujeito se viu aprisionado pelos significantes do Outro cuja demanda é de que aceite o alimento.

Ao presentificar o nada através de uma recusa generalizada, o sujeito se torna mestre da onipotência, cabe apenas a ele fazer-se viver ou não. "A partir daí, é ela (a anoréxica) quem depende por seu desejo, é ela quem está à sua mercê, à mercê 
das manifestações de seu capricho, à mercê da onipotência de si mesma" (Lacan, 1956-57/1995: 190).

É inegável que, por sua própria estrutura de funcionamento, a anorexia é um sintoma que traz em si uma tentativa de separação do Outro. O "não!" anoréxico, o comer nada da anorexia, aponta a dissociar precisamente a dimensão do desejo daquela da demanda, ou seja, a falta não pode ser reduzida a objeto algum, tampouco ao alimento. Ao mesmo tempo, não podemos deixar de apontar que há uma diferença entre capricho e desejo, entre o "não" como possibilidade de expressão subjetiva e a radicalidade do nada, entre um movimento que visa o distanciamento do Outro e uma outra manobra que requer sua presença como refém do sujeito.

$\mathrm{Na}$ singularidade de cada caso, o analista às voltas com a anorexia terá que lidar com algumas questôes aqui destacadas, tais como a relação entre o sujeito e o Outro, o nada, o capricho, a alienação e a tentativa de separação, que corresponde a uma pseudo-separação. Nem bem-sucedida, nem totalmente malograda, essa tentativa de separação aspira ao desejo. É justamente pelo viés do desejo que a falta pode ser afirmada e que o trabalho analítico pode apostar na separação.

\section{REFERÊNCIAS BIBLIOGRÁFICAS}

Bastos, A. (2003). Entre o ser e o sujeito: a alienação. Em Pinheiro, T. (Org.). Psicanálise e formas de subjetivação contemporâneas (pp. 137-149). Rio de Janeiro: Contracapa.

Freud, S. (1950 [1892-1899]). Extratos dos documentos dirigidos a Fliess. Rio de Janeiro: Imago, vol. I, 1996.

- (1950 [1895]). Projeto para uma psicologia cientifica. Rio de Janeiro: Imago, vol. I, 1996.

Lacan, J. (1955-56). O Seminário. Livro 3: As psicoses. Rio de Janeiro: Jorge Zahar Editor, 1988.

. (1956-57). O Seminário. Livro 4: A relação de objeto. Rio de Janeiro: Jorge Zahar Editor, 1995.

- (1958). A direção do tratamento e os princípios de seu poder. Em Escritos (pp. 591-652). Rio de Janeiro: Jorge Zahar Editor, 1998.

. (1960). Posição do inconsciente. Em Escritos (pp. 843-864). Rio de Janeiro: Jorge Zahar Editor, 1998.

. (1962-63). O Seminário. Livro 10: A angústia. Rio de Janeiro: Jorge Zahar

Editor, 2005. 
(1964). O Seminário. Livro 11: Os quatro conceitos fundamentais da psicanálise. Rio de Janeiro: Jorge Zahar Editor, 1986.

Miller, J. A. (2000). A teoria do parceiro. Em Monteiro, E. \& Ribeiro, V. A. (Orgs.). Os circuitos do desejo na vida e na análise (pp. 153-207). Rio de Janeiro: EBP - Contracapa.

Rabinovich, D. (1993). La angustia y el deseo del Otro. Buenos Aires: Manantial.

Recalcati, M. (2001). Os dois "nada" da anorexia. Correio: Revista da Escola Brasileira de Psicanálise, 32, 26-36. São Paulo.

Soller, C. (1997). O sujeito e o Outro II. Em Fink, B. \& Jeanus, M. (Orgs.). Para ler o seminário 11 de Lacan. Rio de Janeiro: Jorge Zahar Editor.

Wachsberger, H. (1998). Questions orales. Les Feuillets du Courtil, 15, 11-16. Paris.

Recebido em 9 de março de 2006 Aceito para publicação em 10 de abril de 2006 